\title{
PARTICIPAÇÃO DAS MULHERES TRABALHADORAS DAS FÁBRICAS TÊXTEIS NOS BOICOTES E PARALIZAÇÕES NO PERÍODP DE 1889 A 1930 NA CIDADE DE SÃO PAULO
}

\author{
Mariana Cunha Bhering (Mestre em Educação - Universidade Federal de São Carlos)
}

\section{RESUMO}

Com o fim da escravidão, a liberação para a monocultura viabilizou-se a produção de café, a produção têxtil entre outros. A partir de 1889 nas fábricas têxteis a grande maioria eram mulheres e menores de idade que recebiam os menores salários e eram tidos como mais fáceis de disciplinar. As instituições como o Centro de Centro dos Industriais Fiação e Tecelagem, refere-se muitas vezes por envolvimento em paralisações criaram meios de registrar o que era considerado um comportamento contra a ordem, por meio das cartas circulares os donos das fábricas trocavam informações sobre trabalhadores que exigiam melhores condições de trabalho ou tivesse um outro comportamento não aceito. A atividade do trabalho será tomada como fio condutor da análise do problema da mulher, pois, deste surgem os empecilhos ou incentivos a sua participação política e que gera a problemática da pesquisa, de que maneira a mulher participava das organizações de movimentos e quais eram o discurso e práticas dos patrões. Desse modo, as cartas circulares revelam a participação de mulheres nas mobilizações e perseguição dos patrões para garantir a não contratação delas em outras fábricas.

Palavras-chave: mulheres, trabalho, participação.

\section{PARTICIPAÇÃO DAS MULHERES TRABALHADORAS DAS FÁBRICAS TÊXTEIS NOS BOICOTES E PARALIZAÇÕES NO PERÍODP DE 1889 A 1930 NA CIDADE DE SÃO PAULO}

A atividade do trabalho será tomada como fio condutor da análise do problema da mulher, pois, deste surgem os empecilhos ou incentivos a sua participação política e que gera a problemática do artigo, de que maneira a mulher participava das organizações de movimentos e quais eram o discurso e práticas dos patrões.

No momento em que iniciava a implantação de indústrias no Brasil e constituição de uma base operária no século XIX, a Europa fervilhava com a organização do proletariado em partidos para derrocada do Capitalismo. Com a chegada massiva dos imigrantes europeus, que se deslocaram em sua maioria para São Paulo e Rio de Janeiro, trouxeram além das ideologias, os Centros de Cultura, locais que surgiram as primeiras organizações de trabalhadores, Uniões, Alianças, Ligas e sindicatos.

As únicas associações de trabalhadores reconhecidas pela lei eram as de auxílio mútuo e as cooperativas, isto é, as que não criavam conflito entre empregados e empregadores ${ }^{1}$.

SIMÂO, Aziz, Sindicato e Estado, São Paulo, Dominus, 1966, pp. 160-165 


\section{SEMINÁRIO DE PESQUISA EM CIÊNCIAS HUMANAS - SEPECH \\ Humanidades, Estado e desafios didático-científicos \\ Londrina, 27 a 29 de julho de 2016}

Porém, a repressão a qualquer movimento era intensa, qualquer manifestação era considerada uma ameaça ao bom funcionamento das fábricas. Os sindicatos não eram reconhecidos e não tinham o direito de se pronunciar.

Com a greve de 1917, os anarquistas idealizaram que uma organização para uma Greve Geral Revolucionária, culminara na queda da burguesia. Todavia, nos anos seguintes, a polícia intensificou a ação violenta, até a década de 30, quando finalmente a classe operaria alcançou as leis que garantiriam alguns direitos trabalhistas. Contudo, a formação do Bloco Operário e Camponeses (BOC), a partir de 1927, inicia uma participação política operaria decisiva na sociedade brasileira, em que a classe trabalhadora se apresenta um partido eleitoral e parlamentar que busca desenvolver sua pratica política fora dos canais institucionais abertos pela instituição das leis trabalhistas. $^{2}$

Os trabalhadores produziram jornais de grande importância na mobilização e conscientização da classe trabalhadora. Em março de 1906, o periódico La Battaglia, fundado em 1903 por Oreste Ristori, registra a repressão vigente "A polícia, seja de dia ou de noite, viola os domicílios à vontade; nas vias públicas, prende à toa e não raro consegue os cidadãos; nos conflitos pacíficos entre capital e trabalho, os grevistas são presos nos seus domić́lios, as ligas operárias invadidas pelos esbirros e, como aconteceu ultimamente em Santos, na greve dos estivadores, representantes das ligas são presos como malfeitores." 3

No jornal A Terra Livre em 1906, as operárias Tecla Fabri, Teresa Cari, Maria Lopes escrevem um artigo questionando a ausência e certo "descaso" com a luta operária por parte das mulheres nas de greve de 1906:

Nós passamos indiferentes pelo meio dos grevistas que enchiam as ruas da cidade e fomos trabalhar, mostrando que não tínhamos sentimentos, que não tínhamos sangue nas veias. E, no entanto, naquela multidão estavam nossos pais, nossos irmãos, nossos noivos, por entre os quais nós passamos sem pensar que eles reclamavam um direito para nós também. E assim demonstramos ainda que não tínhamos afetos de família nem amor! (A Terra Livre, São Paulo, $13,6,1906)$

Ainda neste artigo fazem um apelo a participar feminina na luta e descreve a importância do apoio dos jornais operários, mas explica que não foi suficiente para as suas reivindicações serem ouvidas:

(...) É justo recordar que já por vezes alguns amigos, nas colunas do Avanti!, de La Battaglia e da Terra Livre, surgiram em nossa defesa, e as suas palavras não foram ouvidas. Mas esperemos que não nos deixeis, a nós também, pregar no deserto. Devemos demonstrar enfim que somos capazes de exigir o que nos pertence; e se todas forem solidárias se nos acompanharem nesta luta, se nos derem ouvidos, nós começaremos por desmascarar a cupidez dos patrões sanguessugas. (A

2 BLASS, Leila Maria da Silva. Imprimindo a própria história. O movimento dos trabalhadores gráficos de São Paulo no fins dos anos 20. Edições Loyola - São Paulo, 1986. p. 14

3 BEIGUELMEN, Paula. Os companheiros de São Paulo. Teses política 3. São Paulo: Global Editora, 1981 


\section{SEMINÁRIO DE PESQUISA EM CIÊNCIAS HUMANAS - SEPECH \\ Humanidades, Estado e desafios didático-científicos \\ Londrina, 27 a 29 de julho de 2016}

Terra Livre, São Paulo, 13.6.1906)

Uma parte das mulheres eram presente nas lutas, e com o passar do tempo foram conquistando mais espaço nos movimentos, tanto na elaboração de jornais dos sindicatos nascentes, como na luta nas ruas tão reprimida pelas outras instituições.

"...A Companhia Fabril Paulista em virtude da última greve, expulsou as operarias cujos nomes constam na lista anexa que V V SS se dignarão de arquivar

Venho a pelo comunicar V. V. S.S. que, em virtude das providências tomadas por este centro junto a Delegacia Geral e da Diretoria de Investigações da Polícia, a reabertura da Companhia Fabril Paulista operou-se na mais perfeita ordem, sem o mínimo incidente desagradável. ..."

A imagem da participação feminina, em parte foi registrada por relatórios higienistas, policias imprensa operária e outros. Para a realização da pesquisa terá como principal fonte primária os registros do âmbito industrial, ou seja, a visão dos patrões sobre os operários e operárias. Destas fontes as circulares das indústrias, documento elaborado pelos patrões para circular entre os mesmos, com informações diversas para proporcionar um bom funcionamento das fábricas. As pessoas citadas nos documentos eram consideradas baderneiras ou recomendadas para trabalhar em outra fábrica. Também tornam evidente este o registro da participação de mulheres, em boicotes, greves, e como consequência demissões e não recomendação para outras fábricas. Nas circulares também é comum o registro de reportagem de jornais operários, alertando os patrões das informações que poderiam causar desordem no ambiente da fábrica.

\section{PRESENÇA E PARTICIPAÇÃO DA MULHER NO SETOR TÊXTIL}

No município de São Paulo, segundo os dados do censo populacional de 1920, as mulheres representavam $29 \%$ do total de trabalhadores empregados em todos os ramos da indústria, mas no setor têxtil essa participação saltava para 58\%. Já no Rio de Janeiro, então Distrito Federal, a participação das mulheres entre os trabalhadores na indústria era ligeiramente inferior a São Paulo, 27\%, mas no setor têxtil era de apenas $39 \%{ }^{5}$

As autoridades e os homens de ciência do período consideravam a participação das mulheres incompatível com a sua constituição biológica. Os argumentos criados ou reproduzidos e até classificações preconceituosas que pregaram converteram-se em códigos que aos poucos passaram a reger as relações entre os sexos, bem como entre as diferentes classes sociais e grupos étnicos. Só muito recentemente a figura da "mulher pública" foi dissociada da imagem da prostituta e pensada sob os mesmos parâmetros

4 Circular n. 26 Centro dos Industriais Fiação e Tecelagem de São Paulo. Arquivo

5 BATALHA, Claudio Henrique Moraes. O movimento operário na primeira República. Rio de Janeiro: Zahar. P.10 


\section{SEMINÁRIO DE PESQUISA EM CIÊNCIAS HUMANAS - SEPECH \\ Humanidades, Estado e desafios didático-científicos \\ Londrina, 27 a 29 de julho de 2016}

pelos quais se pensa o "homem público", isto é, enquanto ser racional dotado de capacidade intelectual e moral para a direção dos negócios da cidade. ${ }^{6}$

Os trabalhadores da indústria fabril constituíram uma cultura própria e foram por isso, perseguidos pelas forças políticas, no Brasil e vários países outros países da América Latina. As "escolas modernas" criadas pelos libertários, estavam em vários estados e foram destruídas pela polícia, seus jornais foram queimados e suas manifestações reprimidas. ${ }^{7}$

Boris Fausto ao abordar a história do movimento operário principalmente em São Paulo e Rio de Janeiro, no contexto social, econômico e político, também analisa o movimento anarquista, os primeiros grupos socialistas, reflete sobre os conflitos fabris, as conquistas das primeiras leis trabalhistas e as modalidades de repressão, greve de 1917 e outras:

O ano de 1919 e os três primeiros meses de 1920 delimitam o momento mais alto da conjuntura, coincidindo com o fim da guerra e a expansão da vaga anticapitalista na Europa. São Paulo reaparece como centro das mobilizações; com 64 greves na Capital e 14 no interior, em 1919, onde se inclui a grande paralisação do mês de maio que abrange, só na Capital, mais de 45000 trabalhadores, e a greve generalizada do mês de outubro. Significativamente, crescem os movimentos que mencionam entre seus objetivos o reconhecimento dos sindicatos ou expressam a solidariedade de classe. Na Capital, 12 greves além das duas mobilizações de maio e outubro - visam ao reconhecimento da organização sindical pelos patrões, enquanto 8 são desfechadas por razões de solidariedade. (FAUSTO, 161-162)

A disciplina rígida e a hierarquia eram fontes de atritos entre trabalhadores e mestres. Segundo Fausto no plano afetivo multiplicou-se as críticas aos comportamentos dos mestres, resultando em grandes eclosões coletivas:

Assim, os trabalhadores das fábricas Aliança e Cruzeiro deflagraram a primeira grande greve têxtil da Capital da República (agosto de 1903) porque uma operária, ao voltar da maternidade, é despedida pelo mestre com quem tivera um filho. (FAUSTO, 115)

A greve geral de julho de 1917 em São Paulo abriria uma conjuntura histórica que se estenderia até 1920 , define a princípio da emergência do movimento social de base operária, nos centros urbanos do país. Emergência que, no plano das coletivas reflete em vários níveis, que Fausto coloca como maior número de greves da História brasileira até a Segunda Guerra Mundial; nas maiores manifestações de massa, no surgimento de uma impressa operária, na modificação das expectativas de vida. ${ }^{8}$

6 RAGO, Margareth. "Trabalho feminino e sexualidades" in História das mulheres no Brasil. PRIORE, Mary Del - -3. ed. - São Paulo: Contexto, 2000. p. 604

7 RAGO, Margareth. "Trabalho feminino e sexualidades" in História das mulheres no Brasil. PRIORE, Mary Del - -3. ed. - São Paulo: Contexto, 2000. p. 604

Fausto, Boris. Trabalho urbano e conflito social (1890 - 1920). Difel. Rio de Janeiro e

São Paulo. 1976. P. 159 


\section{SEMINÁRIO DE PESQUISA EM CIÊNCIAS HUMANAS - SEPECH \\ Humanidades, Estado e desafios didático-científicos \\ Londrina, 27 a 29 de julho de 2016}

Eric Hobsbawm faz uma abordagem sobre os diversos mundos do trabalho operário, e revela que o trabalho feminino era uma necessidade das famílias pobres. Quando as mulheres trabalhavam fora, antes ou depois do casamento, caso se separasse ou enviuvassem ou o marido não ganhasse o suficiente para manter a esposa e a família. Convencionalmente, as mulheres tinham o objetivo de trabalhar por salários fora de casa até se casar, considerava uma fase temporária, que pertenceria ao proletariado, mas não mais como trabalhado, mas como esposa, dona-de-casa e mãe. ${ }^{9}$

Para Hobsbawm a luta pré-industrial dos pobres além de produzir um espaço para mulheres participarem ao lado dos homens, mas lhes reservou papel específico e de liderança. Uma ação que poderia ser politicamente decisiva como a marcha das mulheres sobre Versalhes em 1789. No Brasil o período que inicia a urbanização e a industrialização, definiu-se noções de certo ou errado, através dos códigos normativos de conduta, que eram função de médicos higienizas, policiais e industriais; receosos das mobilizações operárias. ${ }^{10}$

As operárias feministas da época denunciaram, é certo, as condições de exploração de trabalho feminina: os baixos salários, a opressão exercida pelos patrões, mas não se restringiram a isso. Também lutaram contra os sindicatos que discriminavam as mulheres e contra a opressão na família operária. ${ }^{11}$

A mobilização dos grupos operários restringiu as condições imediatas, concretas de existência. Do custo de vida, do bairro e da fábrica, portanto, a classe trabalhadora no início do processo de industrialização no Brasil, agia no que tinha acesso, na paralisação do trabalho e realizava movimentos de rua, lutaram por dignidade de ser humano, pelo direito de sobreviver. O proletariado vivia uma situação explosiva, em que as reivindicações estavam relacionadas às precárias condições de existência, que em geral motivo que explodissem greves por melhores condições de trabalho, salário, direito ao repouso ou a "incidentes" ocorridos nas oficinas. ${ }^{12}$

Maria Pena revela que a presença feminina no trabalho era encarada muitas vezes como inimiga e não os capitalistas. No início do século $\mathrm{XX}$, as lutas femininas foram deslegitimadas pelo discurso da classe trabalhadora, em torno das próprias e reivindicação entre elas se destacava a luta pelo fim de maus tratos corporais. ${ }^{13}$

As evidências caminham no sentido de mostrar que, em primeiro lugar, as mulheres foram ativamente combativas nos movimentos operários e grevistas; em segundo lugar, sua combatividade era desorganizada; em terceiro, suas manifestações eram espontâneas e não se originavam de uma prática política calculada e planejada: em quarto, seu caminho à liderança estava obstaculizado pela ideologia patriarcal que lhe designava o lar como seu espaço natural e a considerava uma trabalhadora e uma cidadã

9 HOBSBAWM, Eric J. Mundos do Trabalho. Novos estudos sobre História operária.

Coleção Oficina da História. Rio Janeiro: Paz e Terra, 2000. P. 136

10 RAGO, Margareth. "Trabalho feminino e sexualidade" in História das Mulheres no Brasil. PRIORI, Mary Del (org.). 3 ed . São Paulo: Contexto, 2000. p. 579

11 SOUZA-LOBO, Elisabeth. A classe operária tem dois sexos. Trabalho, dominação e resistência. São Paulo: Editora Brasiliense. 1991, p. 210

12 PENA, Maria Valéria Junho. Mulheres e trabalhadoras: presença feminina na constituição do sistema fabril. - Rio de Janeiro: Paz e Terra. 1981. P. 185

13 PENA, Maria Valéria Junho. Mulheres e trabalhadoras: presença feminina na constituição do sistema fabril. - Rio de Janeiro: Paz e Terra. 1981. P. 188 


\section{SEMINÁRIO DE PESQUISA EM CIÊNCIAS HUMANAS - SEPECH \\ Humanidades, Estado e desafios didático-científicos \\ Londrina, 27 a 29 de julho de 2016}

de segunda ordem; em quinto, seus protestos vinculam-se mais à exploração nas fábricas que a subordinação na sociedade. (PENA, 1981)

$\mathrm{Na}$ participação das mulheres nos confrontos ligados ao seu trabalho, posteriormente conquistariam as regulamentações embora não necessariamente cumpridas. Ao longo do início da República os movimentos operários foram combatidos e a riqueza histórica foi canalizada para organizações controladas pelo Estado. Nessas organizações não havia lugar para mulheres e seu estereotipo frágil era reforçado. "Procurou-se apenas, protegê-la no ambiente do trabalho, mantendo seus serviços garantidos sob o teto doméstico". ${ }^{14}$

Documentos oficiais contrapõem-se com a imprensa anarquista, em que mulheres militantes redigiam artigos para os periódicos: A Terra Livre, A Lanterna, A Plebe, A Voz do Trabalhador e outros. Nesses jornais, as mulheres colocavam questões relevantes a emancipação feminina. ${ }^{15}$

Por outro lado, os documentos policiais e circulares dos industriais divulgavam a lista dos “indesejáveis" e dos "jovens agitadores" que deveriam ser afastados da fábrica e de todo o ramo industrial em que trabalhavam.

Queiram VV. SS. incluir na sua lista de indesejáveis os seguintes nomes de operários que foram desperdícios, como agitadores, pela fábrica Luzitania:

Benedita Cerqueira - Maçaroqueira

Italgina Cerqueira - Maçaroqueira

Augusta Maria Conceição - Maçaroqueira e pelas Indústrias Reunidas

F. Matarazzo - Fábrica Belenzinho:

America Mazzini Montorso - Urdideira

Ersilia Montorso - Tecelã

Anna Vial - Seção Estamparia

João Montorso - Seção Estamparia

Maria Montorso - Seção Estamparia

A consulta a este centro sempre que as fábricas tiverem de receber novos operários é sempre recomendável, pois a operária Benedita Cerqueira tem no nosso arquivo secreto a seguinte indicação: 'Despedida pela fábrica Luzitania por ter, em companhia de outros companheiros, feito paralisar os trabalhos da secção de fiação, em $16.12 .1922^{\prime} \cdot{ }^{16}$

Como revela o documento, as mulheres estavam presentes nos boicotes e greves nas fábricas, elas também por sua participação eram também perseguidas.

"Também eram demitidas por péssimo comportamento" registrado nas circulares no Centro dos Industriais Fiação e Tecelagem. Péssimo comportamento se refere muitas vezes por envolvimento em paralisações.

14 PENA, Maria Valéria Junho. Mulheres e trabalhadoras: presença feminina na constituição do sistema fabril. - Rio de Janeiro: Paz e Terra. 1981. P. 191

15 RAGO, Margareth. Trabalho Feminino e Sexualidade in História das mulheres no Brasil. PRIORE, Mary Del (org.) - 3 ed - São Paulo: Contexto, 2000. P. 600

16 Circular n. 304 do Centro das Indústrias de Fiação e Tecelagem de São Paulo, 19 mar. 1924 citado por RAGO, Margareth. Trabalho Feminino e Sexualidade in História das mulheres no Brasil. PRIORE, Mary Del (org.) - 3 ed - São Paulo: Contexto, 2000. P. 601. 


\section{SEMINÁRIO DE PESQUISA EM CIÊNCIAS HUMANAS - SEPECH \\ Humanidades, Estado e desafios didático-científicos \\ Londrina, 27 a 29 de julho de 2016}

Centro dos Industriais Fiação e Tecelagem.

São Paulo, 21 de maio de 1921

Circular n. 19

Reservada - estritamente confidencial

Prezados Senhores;

No nosso projeto de repressão aos roubos e furtos nas fábricas, repressão que se estende a todos os maus elementos que, nas fabricas, semeiam indisciplina e desordem assinalamos que com inócuo sistema até hoje seguidos pelos nossos associados (de punirem seus maus opera rios com expulsão pura e simples e comunicação dos seus nomes delitos aos outros associados, por intermédio deste Centro) existe uma classe de operários indesejáveis que faz ciclos pelas fabricas do Estado, mal grado os avisos do Centro.

Apoiamos nossa asserção, dentre outros, num exemplo frisante e recente: a operária Maria Theophino foi expulsa da "Fábrica Mariangela" a 30 de abril de 1920, por atos reprováveis. Pois, bem, esta operaria, cujo nome e delito foi comunicado aos associados a 5 de maio de 1920, foi admitida na "Fabrica Luzitania" e dela expulsa a 16 do corrente, também por atos reprováveis. Amanhã por certo, conseguirá colocar-se em outra fábrica, com o mesmo nome ou com nome suposto... ${ }^{17}$

Os chamados de agitadores ou indesejáveis pelos filiados do Centro de Fiação de Tecelagem de São Paulo, trata-se de operarias e operários envolvidos na organização de greves. Algumas circulares são reforçadas com denominações como "confidencial" ou "estritamente confidencial", que exige maior atenção dos filiados.

As operarias e operários procuravam meios de manter-se nas fabricas, quando eram repreendidos em uma fábrica encontravam outra, muitas vezes mudavam de nome. A participação das mulheres também é denominada de agitadoras, por organizar greves:
Amigos e Senhores
Maria Constantini
Cecilda Chiaverini
Argentina Bacelli
Nicolina Paulina
Somos, com alta estima e apreço
Amigos. Crds Obs., Gerente. $^{18}$

Referimo-nos é nossa circular n 301, de 8 do corrente.

Queiram VV SS incluir na sua lista de indesejáveis os seguintes nomes de operarias tecelãs, que foram despedidas pela Companhia Nacional de Tecidos de Juta, como agitadoras:

Além das greves, algo muito frequente nas fábricas eram os furtos de matériaprima, também devidamente registradas pelo Centro de Fiação:

Amigos e senhores,

17 Circular n. 19 Centro dos Industriais Fiação e Tecelagem de São Paulo. Arquivo

18 Circular n. 304. Centro dos Industriais Fiação e Tecelagem de São Paulo. Arquivo 


\section{SEMINÁRIO DE PESQUISA EM CIÊNCIAS HUMANAS - SEPECH \\ Humanidades, Estado e desafios didático-científicos \\ Londrina, 27 a 29 de julho de 2016}

Queiram VV SS incluir na sua lista de indesejáveis os nomes dos seguintes operários que foram despedidos, por motivo de furto, pela Companhia Nacional de Tecidos de Juta:

Miguel Bergamini

Pedro Ferraro

e a operaria abaixo, despedida pela Companhia de Tecido São Martinho, como agitadora:

Maria Bimbati.

Somos. com elevada estima e apreço,

Amigos, Acds. Obds.

Gerente. $^{19}$

A preocupação em reconhecimento do operária indesejável, era constante:

"As fábricas, em regra geral, punem as faltas leves, cometidas pelos operários, adomesticando-os, suspendendo-os, multando-os, rebaixando-os de categoria. Só as faltas realmente graves são punidas com a expulsão e, dado o espírito de justiça e sentimento de humanidade que reina entre nossos industriais, podemos afirmar que os operários expulsos são radicalmente indesejáveis...

Pois bem, somente as fabricas associadas a este Centro, no período que vai do fim de abril até hoje, expulsaram 75 operários. Esses 75 operários, expulsos por haverem cometido faltas graves, podem voltar a trabalhar nas indústrias têxteis, reincidindo nas mesmas faltas, concisos, como estão, de que não lhes faltará trabalho, pois a fábrica não tem elementos para reconhece-los.

O exemplo, convincente que é não pode deixar de impressionar". ${ }^{20}$

Os donos de indústrias ligados ao Centro de Fiação e Tecelagem de São Paulo, começaram a implementar medidas além das cartas circulares com descrição dos "indesejáveis" começaram a fazer registros mais precisos dos que eram expulsos das fábricas, para terem maior controle de seus operários. No circular número 38 o Centro propõe a criação de fichas dos operários com cópias para todos os filiados, tem como exemplo as fábricas de Sorocaba:

...O grande centro manufatureiro, que é Sorocaba, colocou em prática uma medida talvez única nos anais da nossa industriais: queremos nos referir á identificação cinetifica, em massa, de todo o seu operariado. Nas fabricas sorocabanas (e elas são numéricas) não existe UM ÚNICO operariado que não haja deixado na Delegacia Regional a sua ficha completa. Essa implantação de uma medida que, a muitos, poderia parecer antipática e até atentatória á liberdade individual, se fez sem tropeços dignos de registro e as indústrias de Sorocaba colhem hoje o fruto da sua inteligente iniciativa.

De resto, ao identificarem os seus operários, os industriais sorocabanos não fizeram mais do que imitar o que, hoje, se faz no mundo inteiro... ${ }^{21}$

19 Circular n. 312. Centro dos Industriais Fiação e Tecelagem de São Paulo. Arquivo 


\section{SEMINÁRIO DE PESQUISA EM CIÊNCIAS HUMANAS - SEPECH \\ Humanidades, Estado e desafios didático-científicos \\ Londrina, 27 a 29 de julho de 2016}

Ainda nesta carta circular, o gerente comunica os procedimentos a serem adotados pelos donos de fábricas:

Nas nossas fabrica não temos nem ao menos o antiquado sistema de cadernetas e vem daí a privilegiada situação que desfrutam os nossos operários, em detrimento dos seus patrões....

Pois bem, este Centro se propõe PROCEDER A IDENTIFICAÇÃO CIENTIFICA DE TODOS OS operários das fabricas que lhe são filiadas... compreendemos que forçar operários a se apresentarem numa repartição policial será medida passiva de críticas, mas não podemos admitir a hipótese de ficarem feridos melindres si a identificação FOR FEITA DIRETAMENTE PELO CENTRO, SEM INTERFERENCIA ALGUMA DA POLICIA.

... 7) De cada vez que se expulsar um operário, a fábrica que expulsou comunicará ao Centro, dizendo por qual motivo expulsou o operário de ficha número tal.

8) O centro comunicará a expulsão aos seus associados e, depois fazer cópia do retrato arquivado e dos dizeres da ficha do expulso, mandará um exemplar a cada sócio, gratuitamente.

9) Os operários expulsos terão lugar especial no arquivo do Centro e nos das Fabricas. ${ }^{22}$

O Centro de Fiação e Tecelagem, reforça que o antigo sistema de cadernetas não tinha eficiente controle sobre os trabalhadores e acabava os favorecendo. Tais procedimentos elencados pelo gerente permiti elaborar um padrão das fichas de operários e operárias.

\section{CONCLUSÃO}

Hoje existe muitos estudos sobre a história da mulher, mas é necessário resgatar o início desta história. A participação da mulher nas greves seria inevitável no setor têxtil, pois eram a maioria. A postura adotada muitas vezes pelos industriais era a demissão e um registro para não mais ser contratada no setor. Estes eram um dos meios para manter a "mais perfeita ordem". A mulher ao se tornar uma operaria para ajudar no orçamento da casa, rompe fronteiras, participa da luta de direitos. Constatasse não somente a da mulher no trabalho, mas sua importância na fábrica e seu envolvimento nos grupos de boicotes e greves que exigiam determinados direitos num período que a mulher tinha como principal papel zelar pelo lar.

Este cenário de conflito entre trabalhadores contra patrões e Estado, seria inevitável a presença massiva das mulheres, porém, mesmo os sindicatos com ideologias diferentes, com discurso de emancipação da classe trabalhadora são controversos, no mesmo tempo em que os valores da família burguesa patriarcal eram consolidados no Brasil, seu discurso muitas vezes reforça estes valores. A participação de mulheres e homens no período da indústria nascente revela um incomodo por parte dos patrões. Estas cartas circulares mantinham os patrões em alerta, a denominação

21 Circular n. 38. Centro dos Industriais Fiação e Tecelagem de São Paulo. Arquivo

22 Circular n. 38. Centro dos Industriais Fiação e Tecelagem de São Paulo. Arquivo 


\section{SEMINÁRIO DE PESQUISA EM CIÊNCIAS HUMANAS - SEPECH \\ Humanidades, Estado e desafios didático-científicos \\ Londrina, 27 a 29 de julho de 2016}

"estritamente confidencial", significa informações importantes para manter a ordem nas fábricas. E não admitir as operárias e operários.

\section{REFERÊNCIA}

ABREU, Marcelo de Paiva (org.). A ordem do Progresso: cem anos de política econômica republicana, 1889-1989. Rio de Janeiro: Elsevier, 1990

BATALHA, Claudio Henrique Moraes. O movimento operário na primeira República. Rio de janeiro: Zahar.

BLASS, Leila Maria da Silva. Imprimindo a própria história. O movimento dos trabalhadores gráficos de São Paulo nos fins dos anos 20. Edições Loyola - São Paulo, 1986.

CARLINI. Angélica Lucia. Mulheres de bairro de São Paulo. São Paulo, PUC. Dissertação de mestrado - PUC, 1995

CASAGRANDE, Nancy dos Santos. Os Bastidores do Discurso Político Sindical. Dissertação de Mestrado. PUC SP, 1996.

DIAS, Maria Odilia da Silva. Quotidiano e poder em São Paulo - século XIX. São Paulo, Brasiliense, 1984

HANNER, June E. A mulher brasileira e suas lutas sociais e políticas, 1850-1937. São Paulo: Brasiliense, 1981.

HOBSBAWM, Eric J. Mundos do Trabalho. Novos estudos sobre História operária. Coleção Oficina da História. Rio Janeiro: Paz e Terra, 2000.

LEITE, Miriam Moreira. Outra Face do Feminismo: Maria Lacerda de Moura, Miriam Lifchitz Moreira Leite. São Paulo: Ática, 1984.

MATOS, Maria Izilda Santos de. Trama e poder: um estudo sobre as indústrias de sacaria para o café. 3 ed., Rio de Janeiro: Sette Letras, 1997

Por uma história da mulher. Bauru, SP: EDUSC, 2000.

PENA, Maria Valéria Junho. Mulheres e trabalhadoras: presença feminina na constituição do sistema fabril. - Rio de Janeiro: Paz e Terra. 1981.

RAGO, Margareth. Trabalho Feminino e Sexualidade in História das mulheres no Brasil. PRIORE,

Mary Del (org.) - 3 ed - São Paulo: Contexto, 2000. 


\section{SEMINÁRIO DE PESQUISA EM CIÊNCIAS HUMANAS - SEPECH \\ Humanidades, Estado e desafios didático-científicos \\ Londrina, 27 a 29 de julho de 2016}

Do Cabaré ao Lar - A utopia da cidade disciplinar - Brasil 1890-1930, São Paulo, Paz e Terra, 1997.

STOLCKE, Verena. Mulheres e Trabalho. Petrópolis, Estudo Cebrap, 1988.

THOMPSON. E. P. A voz do passado. Rio de Janeiro: Paz e Terra, 1922.

Paulo: Paz e Terra

A Formação da Classe Operária Inglesa. Oficina de História. São

TOLEDO, Edilene. Anarquismo e sindicalismo revolucionário. Trabalhadores e militantes em São Paulo na Primeira República. Ed. Fundação Perseu Abramo, 2004.

PERROT, Michelle. Mulheres Públicas, São Paulo: Unesp, 1998. 